\title{
Gestión de festivales de cine en Bogotá: Más allá de la formación de públicos
}

\author{
Managing Bogota film festivals: Beyond audience
}

\section{Camilo Calderón-Acero}

Corporación Universitaria Minuto de Dios, Bogotá, Colombia

camilo.calderon.aduniminuto.edu.co

https://orcid.org/0000-0003-1383-9799

\section{Resumen}

A partir de entrevistas en profundidad con organizadores de cuatro festivales de cine relevantes y reconocidos que se celebran en Bogotá (Colombia), el presente artículo explora la correspondencia entre los objetivos de las políticas públicas de fomento en cuanto a formar audiencias y las percepciones y experiencias en la práctica. Los discursos de los programadores de Bogoshorts, MIDBO, El Espejo y Smartfilms visibilizan las perspectivas de estos certámenes en tensión y, al mismo tiempo, en diálogo con los propósitos expresados en las políticas del Estado. Por eso también se incluyen testimonios del Ministerio de Cultura y la Cinemateca de Bogotá. Las entrevistas trascienden las cifras de estudios cuantitativos previos para así poner en diálogo diversas voces de la exhibición alternativa. Al final esto permite explorar otras dimensiones de esos eventos, normalmente ignoradas por las políticas públicas, y se puntualizan otros retos para la gestión de un festival de cine.

Palabras clave: Industrias Culturales, Festivales de cine, Exhibición alternativa, Diversidad Cultural, industria cinematográfica.

\begin{abstract}
From in-depth interviews with four organizers of relevant and recognized film festivals held in Bogota, Colombia, this article explores the correspondence between the objectives of public promotion policies; especially in terms of forming audiences and their perceptions and experiences in practice. The speeches of the programmers of Bogoshorts, MIDBO, El Espejo and Smartfilms make visible the perspectives of these events in tension and, at the same time, in dialogue with the purposes expressed in state policies. This is why testimonies from the Ministry of Culture and the Cinematheca de Bogotá are also included. The interviews transcend the figures of previous quantitative studies in order to put into dialogue various voices of the alternative exhibition. In the end this allows to explore other dimensions of these events, usually ignored by public policies, and other challenges are pointed out for the management of a film festival.
\end{abstract}

Keywords: Cultural Industries, film festivals, Alternative film exhibition, Cultural Diversity, Film industry. 


\section{Introducción}

A través de sus políticas públicas, el Estado colombiano ha definido lo que deben ser los festivales de cine en tanto vehículos para la promoción de la diversidad cultural y la formación de públicos. No obstante, no hay suficiente evidencia que a la fecha haya verificado y profundizado si acaso esta expectativa se cumple o no en las prácticas concretas de los certámenes. Esto es más relevante aún considerando que los festivales de cine no sólo exhiben películas, sino que organizan eventos como charlas, talleres, encuentros de la industria y de los diversos mercados culturales, todos los cuales son fundamentales para dinamizar el circuito de la industria audiovisual.

Al mismo tiempo, la organización y realización de este tipo de certámenes ha aumentado en Colombia en lo que va del siglo XXI, por lo tanto, los festivales de cine se han transformado en un objeto de interés para el campo de los estudios en comunicación y cultura. En efecto: En 2002, en Colombia se celebraron 12 festivales de cine en siete departamentos distintos a lo largo y ancho del país. En apenas ocho años, esa cifra casi se quintuplicó: En 2010 se registraron 55 festivales en 22 departamentos (Ministerio de Cultura de Colombia, 2010); y ya para 2017 se contabilizaban 71 eventos de esto tipo en todo el territorio nacional (Ministerio de Cultura de Colombia, 2018, p.27). Este panorama descriptivo refleja cierta diversidad en este circuito:

Entre los eventos que hoy se realizan en el país se destacan festivales de cine al aire libre realizados en pequeñas y bonitas ciudades históricas y coloniales como Barichara, San Agustín, Santafé de Antioquia y Villa de Leyva; festivales temáticos como Festiver (cine verde), Cinexcusa (temáticas sociales), El Espejo e Invitro (especializados en cortometrajes), FesticineKids (cine infantil) y CineToro (especializado en cine experimental); festivales de grandes capitales del país como el de Bogotá, el de Cali y el de cine colombiano en Medellín, ciudades que también tienen festivales alternativos en sectores marginados como el de Ojo al sancocho (Ciudad Bolívar) y el Festival Comuna 13. Últimamente han surgido también festivales con énfasis en los medios digitales como el Festival Audiovisual CC (Creative Commons) y los 140 caracteres (videos inspirados en twitter) (Rivera, 2012).
Aunque el Ministerio de Cultura de Colombia mantiene un registro del volumen y tipos de festivales de cine celebrados en el país, este enfoque sólo ofrece un panorama descriptivo, sin ahondar en las características de cada certamen y sus actores. Frente al rol que el Estado le atribuye a los festivales en tanto instancia formadora de audiencias, la pregunta acerca de si dicha expectativa normativa es compartida o no por otros actores de la escena y si se cumple en las prácticas concretas de diseño, organización y ejecución de estos certámenes y del sector audiovisual, en general.

Con el propósito de comprender las motivaciones y percepciones de diversos actores del sector creativo de los festivales de cine sobre el ámbito de la exhibición alternativa audiovisual, este artículo explora cómo cuatro festivales de cine celebrados en Bogotá perciben su labor y de qué manera la desarrollan. Para ello, realizamos seis entrevistas en profundidad (cuatro a programadores de festivales y dos a representantes de la política públical a través de las cuales, además, este estudio ilumina otras dinámicas que rodean la gestión de este tipo de eventos y que no han sido suficientemente reconocidas en Colombia, visibilizando dinámicas diferentes o complementarias a la ya declarada formación de públicos que surge como central para las políticas estatales.

\section{Marco Teórico}

Para estudiar los festivales de cine deben considerarse como actividades con una característica particular: Ofrecen una oferta de bienes y servicios culturales. Como reconoce García-Canclini (1991): “los productos denominados culturales tienen valores de uso y de cambio, contribuyen a la reproducción de la sociedad y, a veces, a la expansión del capital, pero en ellos los valores simbólicos prevalecen sobre los utilitarios y mercantiles" (p. 42).

Este enfoque enmarca el análisis dentro del campo de estudios de la economía política de la comunicación, en el cual los diversos medios -como el cine-. ofrecen un bien cultural $y$, por lo tanto, se inscriben en las industrias culturales. Por lo tanto, puede explicarse su funcionamiento en relación con las lógicas del mercado capitalista. En ese sentido, la 
economía política de la comunicación y la cultura tiene como principal objeto de estudio "las relaciones sociales (particularmente las relaciones de poder) que constituyen la producción, la distribución y el consumo de bienes simbólicos" (Gómez-García \& Sánchez-Ruiz, 2011, p.2).

De este modo, los festivales de cine ocupan un lugar relevante en la cultura como vehículos que integran nuevas formas de acceso al mercado sin ir en detrimento de la promoción de la identidad cultural. Este tipo de investigaciones amplían el universo académico relacionado al cine en la medida en que, como manifiesta Vallejo (2014), los textos (las películas) han dejado de ser el único centro de interés, en favor de los contextos. Para esta autora, los festivales son objetos de estudio más que idóneos, ya que posibilitan el análisis de los poderes que condicionan la selección y producción de determinadas películas y también los procesos de decisión que hay detrás de estas prácticas. Por ejemplo, una película que haga parte de una selección oficial cuenta con una validación que permitirá ampliar su público e iniciar su tránsito en la exhibición comercial local y en el extranjero.

Un festival de cine, además, establece formas de exhibición diferentes a las del cine comercial y emerge una distinción adicional: en la realización de estos certámenes se juega un nuevo contexto en el cual lo primordial para las comunidades es visibilizarse para incidir:

La innovación en este campo implica la generación de un nuevo producto cultural que es distinto a los anteriores y por lo tanto conlleva a un aumento en la diversidad. Los procesos de creación cultural aportan nuevos productos al mercado y, por lo tanto, flujos económicos que expanden y dinamizan los mercados (López, 2006, p.1).

A partir de la singularidad promovida en y por los festivales de cine, su carácter multidimensional en el que coexisten múltiples intereses se hace evidente. Para Dayan (2013), el festival es un espacio donde actores divergentes se permiten actuar colectivamente. En ese crisol convergen periodistas, agentes de ventas, distribuidores, cineastas, organizadores y la audiencia, entre otros. De hecho, en un mismo evento, ocurren simultáneamente numerosas y diversas dinámicas basadas en las relaciones y motivaciones de estos múltiples grupos de interés. Vallejo (2014) concuerda con esta visión al destacar "la necesidad de entender los festivales no como una suma de eventos al mismo nivel, sino como una red interconectada donde existen relaciones de poder y jerarquías" (p. 22). Este enfoque confirma la necesidad de enmarcar los propósitos de estos certámenes en la indagación mayor sobre los intereses de un grupo específico de la industria cinematográfica en vez de construir una respuesta unívoca y homogénea para todas estas experiencias.

En ese mismo sentido, Peirano (2016) considera los festivales de cine como plataformas globales complejas donde convergen y se superponen prácticas y objetos diversos, como mercados, vitrinas culturales de exhibición y secciones competitivas, así como también múltiples agendas de distintos actores que encarnan múltiples intereses, como los organizadores de los festivales, los agentes de ventas y los mismos profesionales de la industria.

\subsection{Las funciones de un festival de cine}

Dado este objeto de estudio con características multidimensionales tan sugerentes, es necesario y pertinente examinar las dinámicas que rodean la gestión y realización de un festival de cine en Bogotá. Un estudio donde lo importante sea "analizar diferentes aspectos de los eventos señalados que tienen que ver con la participación de las comunidades, la relación con el espacio, la salvaguarda del patrimonio, la apropiación e inclusión social y el reconocimiento de la diversidad, entre otros" (Moscoso et al.,2012, p. 21).

Tales aspectos pueden considerar las funciones de los festivales, los propósitos de un certamen así que incluyen, por ejemplo, los impactos económicos y sociales. Por ejemplo, algunos de los objetivos de un festival puede medirse según las audiencias a las que apela y que asisten. Un estudio así permitiría verificar el impacto social del certamen social en términos de sus públicos, los sectores de la población involucrados y aquellos que resultan excluidos de las actividades culturales (Colombo, 2010). Del mismo modo, es factible realizar estudios de impacto económico que se enfocan en dimensionar la importancia y efectos de una actividad cultural en la economía en un área y período determinados. 
Tanto los estudios sobre el impacto económico como los de impacto social arrojan luces sobre las dinámicas que generan y se producen en los festivales de cine, pero resultan parciales. Un festival puede generar impacto social (buen número de asistentes) y aun así, tener un impacto económico bajo. Por esta razón, hablar del impacto resulta insuficiente y es necesario indagar otras perspectivas que aporten más elementos a la comprensión y alcance del fenómeno. Así, es posible clasificar los festivales según sus repercusiones económicas, turísticas, culturales, sociales y físicas, también (Devesa, Báez, Figueroa \& Herrero, 2012):

1. Repercusiones económicas: “los festivales atraen a espectadores locales y visitantes que gastan su renta en las actividades culturales, así como en otros bienes y servicios relacionados" (p. 3)

2. Repercusiones turísticas: su realización puede ser la clave para la elección de un destino por parte del turista.

3. Repercusiones culturales: al ser un lugar donde se pueden ver y participar en manifestaciones artísticas que no están disponibles el resto del año.

4. Repercusiones sociales: permiten “la creación de un sentido de lugar por parte de los ciudadanos, así como la generación de un espacio social y de interacción" (p. 4).

5. Repercusiones físicas: a raíz de su realización se puede ver modificado el entorno urbanístico y de uso del lugar donde se efectúan.

Montserrat Jurado-Martí (2006) señala que los festivales de cine cumplen también la función de ser "la plataforma de los nuevos realizadores para darse a conocer en el complejo mundo del cine" (p.3). Para llegar a su objetivo identificó, además de la función buscada, las demás que fueron surgiendo a través de la revisión bibliográfica y el trabajo de campo.

De Valck y Loist (2009) analizan diferentes aproximaciones para el estudio de los festivales. Para nuestro análisis resultan más cercanos los estudios que se han ocupado de las formas de progra- mación de un festival (programming). Las autoras mencionan que, entre los enfoques más tradicionales, se cuentan el eje relacionado a los procesos económicos que jalonan los festivales, como lograr visibilidad previa a los estrenos; el eje que se ocupa de los festivales como institución y el eje cuyo foco se dirige a la investigación de festivales como proceso histórico y su relación con un circuito mayor. De Valck y Loist (2009) rescatan dos características necesarias a considerar en los estudios de festivales de cine: "cualquier intento por responder la pregunta de por qué los festivales de cine existen debe gravitar en torno al problema de la distribución" (p.185) y cualquier teorización sobre festivales de cine necesita ser contextualizada' ${ }^{1}$. Esto obliga a abordar las diversas facetas que intervienen en la gestión de los festivales, considerando no solo a los creadores sino que, también, a otros actores como el Estado y los privados e indagar en los procesos que explican su labor.

En el contexto latinoamericano existen trabajos que abordan estas dimensiones. Peirano (2018), por ejemplo, analiza la realización de los festivales de cine en Chile a través de metodologías multisituadas. Su trabajo confirma la necesidad de comprender estos espacios a partir de la diversidad de los actores que congregan. Peirano identifica estos espacios como "nodos" donde se encuentran tanto el cinéfilo interesado en la producción de este circuito como quienes buscan promover sus obras y a ellos mismos como autores, incluso pretendiendo amplificar su reconocimiento a nivel internacional.

Complementariamente, hay interés por conocer más y mejor a las audiencias debido a la complejidad de elementos y procesos presentes en el público que asiste a un festival de cine y cómo, desde esas experiencias, surgen elementos que inciden en la gestión del evento. De ahí que tiene sentido formar públicos, desmarcando y, en cierta medida, confrontando una visión más bien unidireccional desde la cual una institución "ilumina" a un público indeterminado.

Enfoques como el de Alonso (2019) apuntan a dar cuerpo a esas audiencias cinéfilas. En su trabajo, que recopila información de asistentes al $\mathrm{BAFICl}$ y al Festival Internacional de Cine de Mar del Plata, el autor concluye que "hay ciertas características sociodemográficas y, en particular, ciertos aspectos ligados a los gustos, expectativas y consumos 
cinematográficos que condicionan la relación de los espectadores con los festivales" (p.423). El asistente al festival de cine suele llegar a éste con una base cultural previa, la cual suele incidir en el modo como asumirá el evento. Incluso se podría pensar que quienes asisten a un festival de cine ya están condicionados en algún nivel hacia la oferta alternativa y que no hay mayor campo de formación sino de confirmación de intereses:

podría considerarse que los festivales convocan no sólo a públicos especializados en el sentido moderno del término, considerados cinéfilos modernos y eruditos sino también a cinéfilos posmodernos, públicos interesados en un cine de autor, y obras no estrictamente caracterizables como comerciales (Radakovich, 2019, p. 436).

Hallazgos como aquéllos ratifican la necesidad de pensar la formación de públicos más allá de la mera expresión de intenciones, sino ahondar en sus implicancias. Con ello, estamos más cerca de entender al público y a las relaciones que luego se dan en ese circuito entre exhibidores, Estado, festivales y audiencias. Proponemos no sólo tensionar los supuestos sobre los cuales descansa la conceptualización de la formación de públicos, no sólo para visibilizar el trabajo de gestión que implican estos certámenes, sino también para fortalecer el conocimiento sobre este complejo objeto de estudio.

\section{Metodología}

Una primera función atribuida a los festivales de cine en Colombia consiste en la formación de públicos y el apoyo a la circulación cinematográfica alternativa, enfoque consagrado en la legislación relacionada a la actividad cinematográfica. La definición vigente para el 2020 es:

Festival o Muestra de Cine: Evento, único o de periodicidad no inferior a un año, realizado en el territorio nacional, en el que se presenten películas, con el propósito de valorar muestras cinematográficas o de otorgar a ellas premios o distinciones, y que realicen actividades de formación o promoción de cultura o industria cinematográfica. (Ministerio de Cultura de Colombia, s.f.)
Considerando esta definición como básica, el paso siguiente es contrastar esa visión con lo que sucede en el sector a través de lo que sus mismos actores expresan y declaran sobre su gestión. Con el objetivo de ahondar en este aspecto, se escogieron cuatro exponentes representativos dentro de la oferta de los festivales de cine bogotanos para realizar entrevistas a profundidad. Se partió de un número de 19 festivales activos en la ciudad para 2016, según listados del Ministerio de Cultura de Colombia y la ANAFE (Asociación Nacional de Festivales, Muestras y Eventos Cinematográficos y Audiovisuales de Colombia). Los cuatro elegidos fueron Bogoshorts, un festival enfocado al cortometraje; MIDBO, cuyo foco es el documental; El Espejo que apuesta al cine universitario, comunitario e indígena; y SmartFilms, un festival que incluye a las narrativas digitales dentro de su ofer$t^{2}{ }^{2}$. Se incluyeron también entrevistas a los representantes de la política pública cinematográfica tanto a nivel nacional como de la capital, Bogotá. Esta inclusión resultaba imprescindible para contrastar y poner en diálogo la orientación estatal, relacionada con la función de formación de públicos y con lo manifestado en las entrevistas por los cuatro festivales.

La entrevista en profundidad emplea métodos etnográficos, sin llegar a un nivel de indagación empírica como el que se da cuando se analiza el festival en el mismo momento de su realización. Como el foco en este caso está en la visión de los responsables del festival lgestores, organizadores o programadores), las entrevistas permiten conocer sus motivaciones e intereses. Numerosos estudios consideran "los métodos etnográficos como una solución a las limitaciones de las fuentes escritas, cuyos datos muchas veces no se corresponden con las prácticas reales que se producen en el sector audiovisual contemporáneo" (Vallejo, 2014, p.25).

La siguiente sección analiza los enfoques y percepciones resultado de cuatro entrevistas representantes de estos festivales sobre la manera de programar y su visión frente a la actividad de exhibición alternativa, el Estado y los gremios. Sus puntos de vista dialogan, se complementan y contrastan dos entrevistas institucionales: una a un representante de la dirección de cinematografía del Ministerio de Cultura de Colombia y a otra a un funcionario de la Cinemateca de Bogotá. 


\section{Análisis}

\subsection{Estado y oferta festivalera}

En el caso de Bogotá, son dos entidades las que mantienen relaciones más estrechas con los festivales. Por un lado, el Ministerio de Cultura desde la dirección de Cinematografía y, por el otro, la Cinemateca Distrital que es también la Gerencia de Artes Audiovisuales de la ciudad, que impulsa actividades propias de una cinemateca y que está a cargo de la política audiovisual a nivel distrital.

Desde Mincultura, Yenny Chaverra, profesional de la línea de apropiación y formación de públicos, considera que los festivales en Bogotá se pueden diferenciar a partir de los procesos que allí ocurren, pues son de distinta índole.

El BIFF (Bogotá International Film Festival) es un festival que tiene un perfil muy tipo formato festival internacional donde vemos películas que han estado en festivales internacionales muy importantes o premieres latinoamericanas o colombianas. Ahí no tiene mucho sentido incluir producción comunitaria porque no es su foco, pero está Ojo al Sancocho que es comunitario. Digamos que hay una serie de festivales pequeños barriales que se enfocan mucho en lo comunitario. Y ese tipo de festivales se crean mucho en estos entornos porque es la manera de que sus propias producciones circulen (2018) ${ }^{3}$.

En eso concuerda Ricardo Cantor, asesor misional de la Cinemateca ${ }^{4}$, al destacar que dentro de los festivales de cine en Bogotá existe en muchos casos una intención de visibilización de las comunidades y sus propias dinámicas y problemáticas. De esta manera,

los mismos creadores de esas esferas o grupos poblacionales son quienes finalmente al ver que están creando y, de pronto, no encontrar fácilmente lugares en los escenarios de circulación, desarrollan dentro de su proyecto cultural, no solamente unos pilares para la creación, sino también unos escenarios que permitan que lo que están creando circule.

Hay dos tipos de festivales de acuerdo con su alcance: unos ligados a procesos sociales y comunitarios y otros con ejes organizativos y curatoriales más estructurados. A partir de este reconocimiento a su diversidad se deduce que no existe desde el actor estatal una limitación sobre cómo debe ser la oferta, a pesar de que el gobierno nacional ha declarado su interés por promocionar el cine colombiano. Para el Ministerio de Cultura un festival de cine debe ser una ventana para el cine colombiano. Como puntualiza Chaverra (2018), "una de las posibilidades de los festivales de cine es acercar de una manera un poco más amable el público al cine colombiano en un contexto para que sea valorado de una manera más justa, distinta a la competencia en carteleras comerciales".

La promoción de cine colombiano se cruza con la visión de formación de públicos, ya que al cultivar audiencias a través de la alfabetización audiovisual, se genera una afinidad hacia los contenidos nacionales. Para el Estado la formación de públicos es parte de los festivales y la promoción del cine colombiano:

Son la principal ventana del cine colombiano. Tanto de las películas de estreno, como de su diversidad. Entran a complementar allí una oferta y a fortalecer quizás un vacío que encontramos en el comportamiento de la exhibición comercial del cine colombiano (...) Aunque los festivales de cine tienen una duración limitada en el tiempo, esa duración limitada vuelca toda su estrategia de promoción, de formación de públicos y de interlocución con el sector y de visibilización del cine: al cine nacional y latinoamericano (Chaverra, 2018).

Los festivales de cine también cumplen una función descentralizadora de la oferta ya que muchas películas no llegan a la cartelera comercial y ni siquiera salen de las grandes ciudades. De hecho, localidades con menos población o territorialmente más pequeñas ni siquiera cuentan con una sala de exhibición alternativa. Según datos del Ministerio de Cultura de Colombia (2017), para 2016 existían 77 festivales o muestras de cine que se realizaban en 19 departamentos y 24 municipios diferentes; muchos de ellos donde usualmente no existe siquiera oferta comercial. Esto contrasta con la disponibilidad de una sala de cine en el país, la cual se estima en una por cada 28.089 personas y una silla por cada 156 personas. Además de la formación de públicos, los festivales son necesarios en la medida que "los creadores y los productores de las obras audiovisuales necesitan de espacios y plataformas que permitan circular y también explotar comer- 
cialmente sus productos o las obras que realicen" (entrevista con Ricardo Cantor).

En síntesis, el Estado percibe una oferta de festivales de cine en Bogotá diversa, que complementa y refuerza los vacíos de la cartelera comercial y potencia los lazos dentro y entre las comunidades de la industria, las audiencias y el Estado. Sin embargo, estiman, también, que es necesario plantear nuevos horizontes. Como puntualiza Chaverra (2018), urge revisar las coyunturas actuales del audiovisual, en especial en relación a las series web y a las narrativas digitales diversas que se encuentran en expansión.

\subsection{Hacer festivales y no solo formar públicos}

Las entrevistas a los representantes de las instituciones estatales evidenciaron que la formación de públicos como derrotero dentro de la política pública cinematográfica ligada a los festivales no es una camisa de fuerza. Sin embargo, este discurso sí ha calado en la forma como los festivales piensan su actividad. A partir de ese enfoque, se desarrollan otros procesos que vienen de la mano de la formación de públicos y que, en cierta medida, han dado personalidad a este tipo de eventos. En el caso del Bogotá Short Film Festival-Bogoshorts, Felipe Montoya, actual jefe de programación ${ }^{5}$, indicó que

sentimos que debemos hacer un festival precisamente para eso, para la formación de públicos. Precisamente desarrollamos una estrategia muy amplia de formación de públicos porque creemos que es la respuesta a una presencia limitada del cine colombiano en salas y una presencia limitada del cortometraje en otras ventanas de exhibición (...) está bien que haya unos componentes que complementen esa exhibición para que un público se acerque al cortometraje o a ese contenido que está presentando el festival de una manera diferente. Porque si es solo a ver, lo más probable es que el público vaya a sentir un poco de rechazo en primera instancia" (2018).

En ese mismo sentido es la opinión de Felipe Moreno Salazar, gestor cultural y actual programador artístico del El Espejo Festival de cortometrajes y escuelas de cine ${ }^{6}$ :

la cuestión de la formación de públicos es necesaria y debería ser indispensable en todas las cuestiones culturales. No se gana nada con que la misma élite disfrute los productos que esa misma élite realiza. Entonces, sí es necesario no olvidar esa parte importante de la formación de públicos de todos los eventos y muestras de cine y procesos académicos como programas académicos y universitarios.

Ese tipo de posturas donde se alcanza a descubrir el alcance de la formación de públicos no solo como herramienta de los festivales de cine sino como elemento transversal a diversas manifestaciones culturales y artísticas.

De hecho, la formación de públicos también es vista como un objetivo primordial para tener más asistentes. Paola Figueroa Cantino, coordinadora del comité directivo de la Muestra Internacional Documental de Bogotá, MIDBO, destaca la amplia oferta de festivales y cómo la formación los obliga a pensar en impactar y posicionarse con un contenido específico como lo es el documental: “El objetivo es tener un mayor público e ir abriendo y llegando a otra gente, que no seamos los mismos de siempre escuchándonos y viéndonos, pero es una tarea fuerte" 7 .

Un certamen como SmartFilms Festival, que para 2018 cumplía su cuarta versión, también resalta la formación de públicos como característica vital en eventos relacionados con la creatividad. Incluso el certamen amplía su impacto al enfatizar, más que la formación, a que el público sea creador, muy a tono con las nuevas tendencias del consumo y producción colaborativa. Así lo indica Juan Beltrán, su creador y cofundador ${ }^{8}$ :

cada festival y cada proyecto que quiera generar un impacto social tiene que transformar de alguna manera. Sino transforma entonces cuál es la tarea: ¿suministrar ocio que era lo que normalmente se hacía con estos eventos culturales como las ferias, los desfiles o los reinados? No, esto es un espacio donde puedes tener rumba, puedes tener workshops, puedes tener networking, pero también puedes tener una formación y además una vez que entras no eres el mismo cuando sales de los cuatro días.

De este modo, un festival de cine no solo se aborda desde su ejecución sino, además, desde su relación con la industria cinematográfica, a través de la interacción con la oferta de la cartelera comercial. El festival debería tener un leitmotiv, un lugar 
que lo diferencie de esa otra oferta. Al ser interrogados, los responsables de los festivales señalan la importancia de ellos frente a una oferta comercial y cómo se desmarcan.

Los festivales complementan la oferta cinematográfica que le está llegando al público colombiano porque muchas veces están presentando cosas que de ninguna manera van a llegar a las salas de cine comerciales, o que van a servir para comenzar el voz a voz de una película antes de que sea presentada en salas de cine (Felipe Montoya, jefe de programación Bogotá Short Film Festival-Bogoshorts).

De manera similar lo perciben desde la MIDBO, pues el documental no es visibilizado en la oferta comercial en la misma medida que se produce,

es vital el papel que tenemos como festivales en términos de esa otra oferta, es decir, lo que la gente puede llegar a ver allí. Hay constante en el año y tenemos una oferta súper variada que no se encuentra en la oferta comercial. Un mediometraje, un corto experimental o un largo de ensayo no lo vas a tener en una oferta comercial y si lo puedes tener en los festivales. (Paola Figueroa, MIDBO).

Desde esa complementariedad con la oferta comercial es que los festivales logran diferenciar su perfil y dan a la audiencia contenido que de otra forma no llegaría a sus ojos. Esto no solo incluye las exhibiciones sino también la posibilidad de dialogar con los creadores y otros públicos con los mismos intereses artísticos. Como señala Felipe Moreno:

se trata descubrir nuevas cosas, poner lo que no tiene esa demanda comercial, productos audiovisuales que, si no es un festival de cine, no se ven. El festival de cine de alguna manera también ve el cine como un objeto de estudio, ahí se ponen películas que tienen un valor estético mayor al comercial a lo que la gente quiere (Festival El Espejo).

Incluso dentro del circuito alternativo los festivales han ganado espacios como primeras ventanas de exhibición en la medida que los cineclubes y las salas alternativas de artes y ensayo se han opacado. Sin esa red alternativa no se podría consolidar el funcionamiento de los festivales, pues se apoyan en entidades como la Cinemateca Distrital, las universidades y algunas salas de cine alternativo que generalmente se vinculan como socios, aliados o patrocinadores de los eventos. Los festivales son la primera instancia de todas estas otras ventanas de exhibición. Si le va muy bien en los festivales se supone que le va mejor en los otros espacios: "Así, un festival de cine es una ventana permanente de exhibición que usa las otras para seguir haciendo bulla y dándose a conocer para que tenga mucho más apoyo y más películas le lleguen" (Felipe Moreno Salazar, gestor cultural y programador del El Espejo Festival).

Un caso claro de cómo funcionan estas sinergias en el sector alternativo es Bogoshorts.

Si estoy ofreciendo un tipo de contenidos en una sala alternativa a este sector, pues ya me ha formado un público que va a ser más receptivo cuando llegue mi festival. Por eso Bogoshorts tiene las dos: tiene un festival anual que ofrece sus contenidos de manera exclusiva y de manera especial durante un periodo de tiempo determinado, pero también un programa de formación de públicos y de exhibición continua de cortometrajes durante todo el año. En un estreno en Cine Tonalá Bogotá los martes, en exhibiciones al aire libre en Bogoshorts bajo la luna en la Universidad de los Andes, con un conversatorio con sus directores el último viernes de cada mes en la Cinemateca Distrital y muchos otros más (Felipe Montoyal.

Al final, el festival, aunque es una isla cuya subsistencia depende de su misma singularidad, no puede persistir sino se piensa también como parte de un archipiélago interconectado donde hay permanente intercambio con otros actores dentro de ese ecosistema de exhibición alternativa.

\subsection{Las redes de apoyo dentro de la exhibición alternativa}

El trabajo en red de los festivales y su relación con el circuito alternativo es visto como baluarte constitutivo para esta actividad.

Estamos en una alianza con todo ese circuito de distribución alternativa, pues en buena medida la programación de estas salas viene de las apuestas de los festivales, y creo que son nuestros aliados fundamentales, tanto por el público que tienen y el espacio que brindan para poder estar nosotros con 
nuestras propuestas también allí (Paola Figueroa, MIDBO).

Los festivales han desarrollado estrategias de comunidad como la constitución de la ANAFE (Asociación Nacional de Festivales, Muestras y Eventos Cinematográficos y Audiovisuales de Colombial?, con el fin de generar espacios cohesionados no solo para alianzas sectoriales sino para su intercomunicación con las instancias gubernamentales.

De hecho, en los festivales investigados es común encontrar términos como cercanía, aliados, festivales hermanos o colaboraciones donde las muestras de un festival se rotan en los escenarios del otro. Si bien es cierto se pueden pensar como competidores, se han logrado redes de trabajo que incluso llevan a que invitados internacionales asistan a más de un festival cuando acuden al país.

Es aún tarea pendiente pensar, más allá de lo coyuntural y específico, sinergias duraderas donde el gremio se apoye más, menos dependencia estatal y más interacción con la industria privada. Para Juan Beltrán de SmartFilms es mejor no solo depender de la financiación estatal:

considero que depender de los espacios de un Estado me amarra y la creatividad es mucho más que eso. Si le damos el poder a esa imaginación y creatividad pueden salir cosas que hasta puedan ayudar al Estado, entre esas pensar que no me voy a fortalecer solo por él sino también por inversión privada.

Desde la institucionalidad se plantea la necesidad de seguir propiciando no solo escenarios de formalización, sino la interlocución con un gremio que en la medida que se organiza busca mayor protagonismo en la toma de decisiones dentro de la industria audiovisual.

Es un campo de tensión, pero sin duda es importante concertar, encontrar y discutir formas que incentiven la circulación de otros contenidos. Es decir, si nosotros no exponemos a los públicos a otros contenidos no va a haber interés, ni demanda, ni apropiación de esos otros contenidos por los públicos (Ricardo Cantor, Cinemateca).

Garantizada una oferta diversa, formalizada y organizada, los festivales perfilan que la sobreoferta en el calendario o las dificultades de recursos se puedan resolver de formas más efectivas. Aún el sector de festivales, así como la propia industria audiovisual colombiana, se encuentra en consolidación; por lo cual, de lo que se construya depende el futuro de estas iniciativas culturales.

Al final el balance frente a labor estatal se inclina, según lo expresado por los festivales, hacia el lado positivo de la balanza, en la medida que se entiende que tanto gestores como entidades deben trabajar de la mano para esa promoción de los contenidos alternativos y más aún con los retos que plantea la distribución multiplataforma y digital.

\section{Conclusiones}

Las entrevistas en profundidad a los representantes de los festivales de cine en Bogotá visibilizan elementos en común acerca de la visión del cine y la realización de un festival. Festivales grandes como Bogoshorts y la MIDBO han conquistado espacios y se han transformado en referentes de la ciudad; $\mathrm{El}$ Espejo, que se orienta más hacia el cine universitario y comunitario, donde la exhibición es un espacio de interlocución entre los poderes y la comunidad; 0 SmartFilms donde las nuevas tecnologías dan paso a la creatividad en múltiples formas y formatos.

Cada uno de ellos resalta el valor del cine como formador de públicos, no siendo ésta la única orientación válida. Por lo tanto, recalcan la necesidad de una interlocución constante entre los miembros del gremio y el Estado. Al Estado se le atribuye un rol activo como promotor de iniciativas que elevan la actividad de exhibición alternativa con financiación y otros elementos de fomento y capacitación. Sin embargo, todavía persiste el reclamo por mayores recursos, máxime cuando el número de festivales en el país aumenta día a día. La sostenibilidad de este tipo de eventos se convierte así en uno de los mayores retos para su supervivencia, de la mano de su propia formalización como organizaciones e incluso como empresas.

Explorar la correspondencia entre la política pública cultural en materia de festivales de cine con su realidad práctica, reveló matices en torno al derrotero de la formación de públicos. Los festivales, deseosos de ampliar el acervo cultural de sus asistentes, con- 
sideran que la formación de públicos es constitutiva dentro de las acciones del festival y que afianza su actividad.

Se encontró un interés reciente desde la institucionalidad por formalizar este sector y la importancia que ha ido ganando, no solo para el público, sino para las entidades que pueden llegar a ser socias o colaboradoras. Los mismos festivales han ido fortaleciendo sus estrategias para asegurar su continuidad, así que no solo hay formación de públicos sino espacios de conversación, de industria, talleres, clases, conferencias, muestras itinerantes y otras actividades durante el año. De hecho, la investigación evidencia cómo los festivales funcionan en la medida que en su ejecución interviene no solo el Estado sino una serie de entidades y organismos interesados en la cultura, de suerte que se conforma una red de apoyo, la cual podría ser una fuente de estudios posteriores.

Las muestras y festivales de cine en Bogotá se están constituyendo en una alternativa atractiva y sostenible frente a la oferta comercial, incluso siendo complementaria y creando alianzas respecto a la exhibición.

Mientras la asistencia a salas de cine comercial vive sus peores momentos, los festivales llenan todas las localidades noche tras noche. Un fenómeno que da cuenta, no solo de la importancia, sino también de la necesidad de su presencia para el mantenimiento de las culturas cinematográficas (Vallejo, 2014, p.36).

Los hallazgos de este estudio abren un lugar para conocer más este sector. Ante una oferta que cada año crece, cabe pensar qué ocurre desde el lado del consumo y su relación con la oferta. Con el cine colombiano sucede una paradoja en los últimos años: se ha incrementado la producción, pero menos gente lo está yendo a ver. Caso similar debería analizarse en posteriores estudios sobre cómo son las audiencias de los festivales de cine en Bogotá y en el país.

Del mismo modo, no es posible desligar a las nuevas tecnologías, ya que hacen parte de ese nuevo escenario audiovisual y allí es donde existen más oportunidades de seguir ampliando la diversidad. Este futuro cada día más cercano abre un espacio en donde los festivales pueden seguir siendo determinantes, dada toda su trascendencia dentro del escenario de difusión y exhibición alternativa.

\section{Notas}

1. Traducción propia del original.

2. La investigación constó de una parte cuantitativa donde se caracterizaron los 19 de festivales de cine bogotanos. Los hallazgos en dicha etapa permitieron evidenciar tendencias dominantes en la programación. Las entrevistas en profundidad buscan complementar lo encontrado a partir de información cualitativa de cuatro festivales representativos de esas tendencias encontradas.

3. Comunicación personal realizada el 17 de julio de 2018.

4. Comunicación personal, 5 de julio de 2018.

5. Comunicación personal, 28 de agosto de 2018 .

6. Comunicación personal, 6 de agosto de 2018.

7. Comunicación personal, 1 de septiembre de 2018.

8. Comunicación personal, 13 de julio de 2018.

9. La ANAFE se creó en el año 2011 y para 2016 contaba con 54 festivales, muestras y eventos cinematográficos como miembros. 


\section{Referencias}

Alonso, J. M. (2019). Vínculo entre públicos y festivales: BAFICl y Mar del Plata. Imagofagia, (19), 404-426. http://www.asaeca.org/imagofagia/index.php/imagofagia/ article/view/1777

Colombo, A. (2010). "Impacto social en la audiencia de un festival". En M. Cuadrado (Ed.), Mercados culturales: doce estudios de marketing (pp. 59-73). Barcelona: Editorial UOC.

Dayan, D. (2013 [2000]). "Looking for Sundance: The Social Construction of a Film Festival. En D. Iordanova (Ed.), The Film Festival Reader (pp. 45-58). St Andrews: St Andrews Film Studies.

De Valck, M. \& Loist, S. (2009). "Film festival studies: An overview of a burgeoning field". En D. Iordanova \& R. Rhyne (Eds.), Film Festival Yearbook 1: The Festival Circuit (pp. 179-215). St. Andrews: St. Andrews Film Studies.

Devesa, M., Báez, A., Figueroa, V. \& Herrero, L. (2012). Repercusiones económicas y sociales de los festivales culturales: el caso del Festival Internacional de Cine de Valdivia. EURE: revista latinoamericana de estudios urbano regionales, 38(115), 95-115. https://dx.doi.org/10.4067/S0250-71612012000300005

García-Canclini, N. (1991). El consumo sirve para pensar. Diálogos de la Comunicación, (30), 6-9.

Gómez-García, R. \& Sánchez-Ruiz, E. (2011). La economía política de la comunicación y la cultura. Tradiciones y conceptos. Portalcomunicacion.com. InCom-UAB, 1-11. http://portalcomunicacion.com/lecciones.asp

Jurado-Martín, M. (2006). Los festivales de cine en España: incidencia en los nuevos realizadores y análisis del tratamiento que reciben en los medios de comunicación [tesis doctoral sin publicar]. Universidad Complutense de Madrid. http://eprints.ucm. es/7306/

López, 0. (2006). Las relaciones entre concentración, competencia y diversidad de contenidos en los mercados de la televisión: revisión bibliográfica y lineamientos para un estudio en Colombia [inédito].

Ministerio de Cultura de Colombia. (2018). Anuario Estadístico de Cine Colombiano 2017. https://mincultura.gov.co/areas/cinematografia/estadisticas-del-sector/Documents/Anuario\%20Estad\%C3\%ADstico\%20Cine\%20Colombiano\%202017.pdf

Ministerio de Cultura de Colombia. (2017). Anuario Estadístico de Cine Colombiano 2016. www.mincultura.gov.co/areas/cinematografia/estadisticas-del.../Anuario2016. $\mathrm{pdf}$

Ministerio de Cultura de Colombia. (2010). Informe de gestión 2002 - 2010. Bogotá. http:// www.mincultura.gov.co/SiteAssets/documentos/Ministerio/Informemincultura.pdf

Ministerio de Cultura de Colombia. (s.f.). Cartilla normas del cine en Colombia. https:// www.mincultura.gov.co/areas/cinematografia/Legislacion/Documents/Cartilla\%20-\%20Normas\%20del\%20Cine\%20en\%20Colombia.pdf 
Moscoso, F., Ramírez, J., Andrade, N., Machicado, J., Mordo, A., González, E., \& Rodríguez, L. (2014). Impacto económico, valor social y cultural de seis festivales en Colombia en 2012. Bogotá: Universidad EAN.

Peirano, M. (2018). Festivales de cine y procesos de internacionalización del cine chileno reciente. Cuadernos.Info, (43), 57-69. https://doi.org/10.7764/cdi.43.1485

Peirano, M (2016). Pursuing, resembling, and contesting the global: the emergence of Chilean film festivals. New Review of Film and Television Studies, 14(1), 112-131. https://doi.org/10.1080/17400309.2015.1109345

Radakovich, R. (2019). Festival empieza con fe. Públicos de festival. Imagofagia, (19), 427451. http://asaeca.org/imagofagia/index.php/imagofagia/article/view/1791

Rivera, J. (2 octubre, 2012). "Festivaliar": un verbo para cinéfilos. Blogs El Tiempo. http:// blogs.eltiempo.com/eltiempo-del-cine/2012/10/02/festivaliar-un-verbo-paracinefilos

Vallejo, A. (2014). Festivales cinematográficos. En el punto de mira de la historiografía fílmica. Secuencias. Revista de Historia del cine, (39), 13-42. https://revistas.uam. es/secuencias/article/view/5838

- Sobre el autor:

Camilo Calderón es Comunicador Social-Periodista. Magister en Industrias Culturales de la Universidad Nacional de Quilmes (Argentina), énfasis en audiovisuales y multimedia. Su interés investigativo es la industria audiovisual y desde 2017 es docente universitario en cátedras de periodismo digital y gestión cultural.

\section{- ¿Cómo citar?}

Calderón, C. (2020). Gestión de festivales de cine en Bogotá: Más allá de la formación de públicos. Comunicación y Medios, (42), 108-119. https://dx.doi.org/10.5354/07191529.2020.57177 